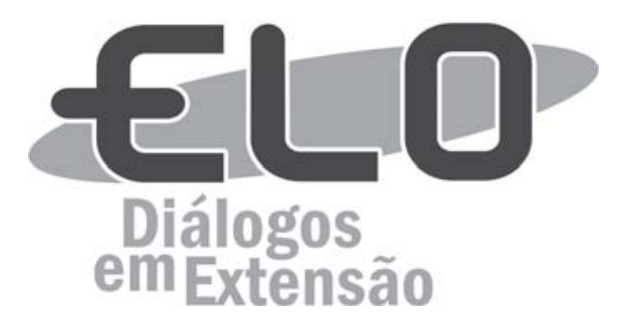

\title{
Proposta metodológica para formação de merendeira das escolas públicas do municipio de Palmas - TO
}

Viviane Ferreira dos Santos ${ }^{1}$, Caroline Roberta Freitas Pires ${ }^{2}$, Hellen Christina de Almeida Kato ${ }^{3}$, Diego Neves de Sousa ${ }^{4}$

\begin{abstract}
Resumo: As merendeiras desempenham uma importante tarefa na melhoria do perfil nutricional, qualidade e segurança da alimentação dos escolares, impactando diretamente na saúde dos alunos. O objetivo deste estudo foi desenvolver oficinas educativas para capacitar e qualificar merendeiras, com ações de nutrição e segurança alimentar. Trata-se de um relato de experiência de caráter descritivo observacional, realizado nos meses de agosto e setembro de 2016, utilizando-se de metodologia ativa. As oficinas foram divididas em: conhecimento, objetivo e aplicação da Resolução da Diretoria Colegiada RDC 2016; microrganismos contaminantes de alimentos; tipos de perigos; condições das instalações e equipamentos; processo e valorização para o trabalho. As oficinas tiveram boa adesão dos participantes, sendo capaz de promover debate e reflexão sobre a temática abordada, reconhecendo, assim, a metodologia utilizada uma boa base para elaboração de capacitações.
\end{abstract}

Palavras-chave: Boas práticas. Capacitação. Merendeiras. RDC 216.

Área Temática: Teorias e Metodologias em extensão. Políticas Públicas.

\section{Methodological proposal for training means of public schools in the Palmas - TO municipal}

\begin{abstract}
The soup kitchens play an important role in improving the nutritional profile, quality and safety of school meals, directly impacting the students' health. The objective of this study was to develop educational workshops to train and qualify food, nutrition and food safety activities. This is an experience report of descriptive observational character, carried out in August and September of 2016, using an active methodology. The workshops were divided into six moments being; Knowledge, objective and application of the Resolution of the Collegiate Board of Directors RDC 2016; Dynamics: "passing the ball"; Dynamic: "physical, chemical and biological danger"; Checklist activity; Dynamics: "tree of progress"; Valorization and motivation for teamwork. The workshops had satisfactory results and good adhesion of the participants, thus recognizing the activities in the form of workshop and dynamic good basis for the elaboration of training courses.
\end{abstract}

Keywords: Best practices. Training. Lunch boxes. RDC 216.

\section{Propuesta metodológica para la formación de merenderas de las escuelas públicas del municipio de Palmas - TO}

Resumen: Las merendes desempeñan una importante tarea en la mejoria del perfil nutricional, calidad y seguridad de la alimentación de los escolares, impactando directamente en la salud de los alumnos. El objetivo de este estudio fue desarrollar talleres educativos para capacitar y calificar merendeiras, con acciones de nutrición y seguridad alimentaria. Se trata de un relato de experiencia de carácter descriptivo observacional, realizado en los meses de agosto y septiembre de 2016, utilizando metodología activa. Los

${ }^{1}$ Graduanda em Nutrição, Universidade Federal do Tocantins - UFT (viviany_ferreira@uft.edu.br)

${ }^{2}$ Professora Doutora da Universidade Federal do Tocantins

${ }^{3}$ Mestre em Ciência e Tecnologia de Alimentos da Universidade Federal do Pará

${ }^{4}$ Doutorando em Desenvolvimento Rural pela Universidade Federal do Rio Grande do Sul (UFRGS) 
talleres se dividieron en seis momentos; Conocimiento, objetivo y aplicación de la Resolución del Directorio Colegiado RDC 2016; Dinámica: "pasando la pelota"; Dinámica: "peligro físico, químico y biológico"; Actividad del check-list; Dinámica: "árbol del progreso"; Valoración y motivación para el trabajo en equipo. Los talleres tuvieron resultados satisfactorios y buena adhesión de los participantes, reconociendo, asi, las actividades en forma de taller y dinámica una buena base para la elaboración de cursos de capacitación.

Palabras clave: Buenas prácticas. Capacitación. Merendes. RDC 216.

\section{Introdução}

A Constituição Federal de 1988 e o Estatuto da Criança e do Adolescente asseguram o direito à alimentação saudável e adequada a criança e ao adolescente, assim como o direito à vida, à saúde, à educação e ao lazer (BRASIL, 2012).

A escola é um local estratégico e fundamental para o desenvolvimento do ensino-aprendizagem do alunado, por ser provedor e mantenedor de ações significativas na formação e construção de conceitos que repercutirão por toda a vida de seus educandos (MENEGAZZO et al., 2011).

Os discentes permanecem boa parte do dia nos estabelecimentos de ensino, neste contexto, a escola torna-se referência para implantação de programas que visem à melhoria do ensino e a promoção de hábitos saudáveis (CAMPOS \& ZUANON, 2004). Alguns fatores são determinantes para a permanência dos alunos no âmbito escolar, além das questões educacionais, as quais interferem diretamente no processo de ensino e aprendizagem, tais como: alimentação, saúde, habitação e saneamento (MENEGAZZO et al., 2011).

O Programa Nacional de Alimentação Escolar (PNAE), gerenciado pelo Fundo Nacional de Desenvolvimento da Educação (FNDE), tem como objetivos a melhoria das condições nutricionais, a contribuição para a aprendizagem e o rendimento escolar dos estudantes, sendo a alimentação adequada um dos constituintes que impactam diretamente na qualidade de vida do aluno e seu consequente desempenho intelectual (BRASIL, 2004b).

Diante disso é importante a intensificação de práticas voltadas ao fortalecimento de ações para a política de alimentação escolar, haja vista que, para alguns alunos, principalmente os de camadas mais vulneráveis da população, a merenda escolar constitui a principal refeição do dia e é um fator de estímulo à permanência na escola, evitando altos índices de repetência e evasão (FERNANDES et al., 2014).

Para atender as demandas e necessidades dos alunos, a escola precisa de recursos humanos e técnicos para a promoção e valorização da educação, reconhecendo que o processo de ensino e aprendizagem se estende para além dos profissionais não docentes, a fim de oferecer condições adequadas para o corpo técnico para a realização de atividades que promovam o bem-estar no ambiente escolar (TEO et al., 2010).

O Ministério da Educação publicou em 2004 um documento intitulado "Por uma política de valorização dos trabalhadores em educação: em cena, os funcionários da escola", com verbas destinadas para a capacitação de merendeiras, vigias, porteiros, secretários, auxiliares administrativos e outras funções exercidas no interior das escolas. Essa intervenção reconheceu que, todos os integrantes do âmbito escolar, são protagonistas do processo educativo (BRASIL, 2004a).

Nunes (2000) reconhece, ainda, que as merendeiras e serventes desempenham um papel importante na educação, que não se limita à preparação de alimentos e à higienização dos espaços, o trabalho e a experiência também contribuem para a formação comportamental e ética dos alunos nas relações sociais.

Para melhora do perfil nutricional, qualidade e segurança da alimentação escolar faz-se necessário o protagonismo e a qualificação das merendeiras para preparar e servir adequadamente a merenda escolar, pois além de promover o incentivo à educação alimentar ambiental, também contribui na educação sanitária como instrumento no processo de ensino-aprendizagem das ciências naturais (TEO et al., 2010).

O presente estudo teve por objetivo executar oficinas educativas com a finalidade de capacitar e qualificar merendeiras envolvidas com a alimentação escolar, ações de nutrição em saúde e segurança alimentar, baseadas nas necessidades identificadas para atender, adequadamente, o PNAE nas escolas públicas do município de Palmas - TO. 


\section{Material e métodos}

Trata-se de um relato de experiência, de caráter descritivo observacional, realizado nos meses de agosto e setembro do ano de 2016. Participaram das oficinas 45 merendeiras, em processo de capacitação para atender as exigências do PNAE, todas pertencentes às escolas municipais e estaduais da rede pública de ensino de Palmas - TO. Este projeto foi desenvolvido a partir de um trabalho maior intitulado como "Transferência de Tecnologia para inserção do pescado da agricultura familiar na alimentação escolar" realizado pela Empresa Brasileira de Pesquisa Agropecuária (EMBRAPA) e pelo curso de Nutrição da Universidade Federal do Tocantins - UFT, cujo principal objetivo consistiu na busca de estratégias de inserção do pescado no mercado institucional para o fortalecimento de pescadores artesanais e melhora da segurança alimentar na rede de ensino pública através da oferta de proteína animal de qualidade.

A capacitação ocorreu na Escola Municipal Henrique Talone Pinheiro, localizada no município de Palmas - TO. Para a realização das atividades foi utilizada a metodologia participativa com base na pedagogia de Paulo Freire (1996) que afirma que, para que haja educação, superação e a resolução de problemas, assim como a construção de novos conhecimentos, são necessárias a exposição do indivíduo à situações e experiências prévias, para, assim, uma concretização do processo de aprendizagem.

Para elaboração das oficinas, as merendeiras foram divididas em cinco grupos, com nove integrantes cada, de modo a facilitar o processo de comunicação. A condução das oficinas foi realizada de forma dialógica onde cada pessoa, de cada grupo, esteve envolvida na ação pedagógica, tendo a oportunidade de expor suas ideias, mesmo que de forma rudimentar. Segundo Paulo Freire (2007), a metodologia dialógica, tem como objetivo promover a ampliação da visão de mundo e isso só acontece quando essa relação é mediatizada pelo diálogo.

As temáticas escolhidas para serem abordadas nas oficinas foram definidas a partir dos temas condizentes e atualizados com a capacitação de merendeiras, obtidos em levantamentos bibliográficos (LEITE et al., 2011; LATORRES, 2014). Os conteúdos contemplados em cada oficina foram: a) conhecimento, objetivo e aplicação da Resolução da Diretoria Colegiada RDC 216 no âmbito escolar; b) microrganismos contaminantes de alimentos, realizada pela dinâmica "passando a bola"; c) perigo físico, químico e biológico, desenvolvida com recortes e gravuras para confecção de cartazes; d) condições das instalações e equipamentos, com aplicação da atividade do checklist; e) identificação dos fatores que colaboram ou interferem no processo de trabalho, dinâmica: "árvore do progresso"; f) valorização e motivação para o trabalho em equipe, realizada com textos reflexivos e mensagens motivacionais.

Para a construção das dinâmicas foram utilizados: cartazes com classificação dos tipos de risco para alimentos; figuras de riscos químicos, físicos e biológicos; painéis em formato de árvores; recortes coloridos em formato de folhas, flores e frutos; bolas de isopor; cápsulas de remédios e recorte com frases motivacionais. Todo material foi adquirido com recurso próprio.

\section{Resultados e discussão}

$\mathrm{Na}$ execução das oficinas, adotou-se uma abordagem pedagógica pautada na inter-relação entre os facilitadores e os indivíduos participantes, estabelecendo um momento oportuno para que as merendeiras atuassem e compartilhassem experiências vividas, contribuindo com o processo de formação dos demais envolvidos na capacitação. De acordo com Paulo Freire (2007) as relações dialógicas, por troca de experiências, constituem uma ferramenta para a produção de uma discordância construtiva para implementar as habilidades, decisões e comunicação persuasiva.

Conforme o roteiro estruturado para a condução das oficinas, inicialmente foi elaborado um módulo de apoio com o objetivo de facilitar o acompanhamento dos conteúdos teóricos e que servisse de material de apoio para as merendeiras. Este módulo foi constituído pela descrição da RDC 216 de 15 de setembro de 2004 (BRASIL, 2004c), de forma clara, precisa e interativa, com atividades de caçapalavras, cruzadinhas, frases para completar e aplicação de checklist.

A primeira etapa da capacitação das merendeiras consistiu na apresentação do módulo de apoio e na definição da Resolução que dispõe sobre o Regulamento Técnico de Boas Práticas para Serviços de Alimentação (BRASIL, 2004c), a fim de dar embasamento teórico às merendeiras acerca das atividades a serem desenvolvidas.

A explanação sobre esse documento estabeleceu recursos necessários para um conhecimento prévio sobre a sua aplicação no âmbito escolar, com objetivo de tornar a cozinha escolar um espaço de produção de uma alimentação saudável, visto que, para isso, devem-se considerar, além dos aspectos nutricionais, os aspectos relacionados à segurança e inocuidade dos alimentos. 
Com enfoque nessa temática, o Ministério da Saúde alega, atualmente, o crescente aumento das Doenças Transmitidas por Alimentos (DTA's) e ressalta a importância do controle dos fatores que contribuem para esse crescente índice, como: o aumento das populações, vulnerabilidade de grupos populacionais, processo de urbanização desordenado, produção de alimentos em grande escala e um controle deficiente dos órgãos públicos e privados na qualidade dos alimentos ofertados às populações (BRASIL, 2010).

Após esse momento, para melhor fixação do conteúdo, foi aplicada uma atividade presente no módulo de apoio, onde os atores envolvidos na produção de alimentos foram orientados a completar os espaços com as palavras relacionadas às definições e objetivos da RDC 216 (BRASIL, 2004c) e, ao final da atividade, explanarem sobre as boas práticas de produção de alimentos em unidades escolares.

Proposta semelhante foi desenvolvida por Leite et al. (2011) ao proporem uma estratégia de formação de merendeiras de escolas de Salvador (BA) atendidas pelo PNAE. Os autores elaboraram a capacitação tendo como premissa um material em linguagem didática e acessível para as merendeiras com o objetivo de facilitar o acompanhamento e melhor entendimento do grupo trabalhado. Segundo Germano (2002), a utilização de material didático como apoio às capacitações, melhora a eficácia das atividades pedagógicas e favorece maior atenção e compreensão do assunto abordado.

A segunda atividade da capacitação enfatizou os riscos potenciais de microrganismos contaminantes e causadores de doenças veiculadas por alimentos, com a execução da dinâmica: "Passando a bola". A técnica participativa consistiu em passar bolas de isopor revestidas com glitter entre todos os participantes, onde cada integrante que estivesse com a bola nas mãos, deveria passá-la rapidamente ao colega mais próximo dizendo a frase: "Isso não é meu!".

Ao final da atividade todos os participantes tiveram as mãos "sujas" de glitter. Esta observação conduz a reflexão acerca da presença de microrganismos invisíveis aos olhos, mas presentes no ambiente de preparo dos alimentos, sobretudo quando este apresentar péssimas condições de higiene, sendo ainda disseminado pelos manipuladores através do contato ou contaminação cruzada. Além disso, a técnica também tem por objetivo abordar o compromisso e a responsabilidade com o preparo da alimentação escolar, onde cada profissional envolvido no processo é peça fundamental para a produção de alimentos seguros. Ao final, os participantes puderam compreender as diversas possibilidades de transmissão de doenças, que podem ser veiculadas por meio dos alimentos e seus manipuladores, quando não estabelecida uma rotina higiênico-sanitária adequada.

Soares et al. (2012) fizeram um estudo com merendeiras de uma escola pública do município de Camaçari (BA) e constataram que, apesar dos profissionais possuírem diversos cursos sobre manipulação de alimentos, foi observado um reduzido conhecimento em relação as DTA's.

$\mathrm{Na}$ terceira atividade da capacitação foram abordados os tipos de perigos físicos, químicos e biológicos. Nessa atividade, os grupos receberam vários recortes e figuras representando alguns dos riscos envolvidos no preparo de alimentos. Os integrantes foram orientados a fazerem a distribuição das figuras de acordo com o risco que se associavam (físico, químico ou biológico) seguindo as definições presentes na RDC n 216 (BRASIL, 2004c).

Após debate e discussão entre os grupos, estes apresentaram suas decisões. Nesse momento, cada grupo elegeu um representante para colarem as figuras selecionadas em cartazes com campos definidos de acordo com a classificação dos perigos (Figura 1).

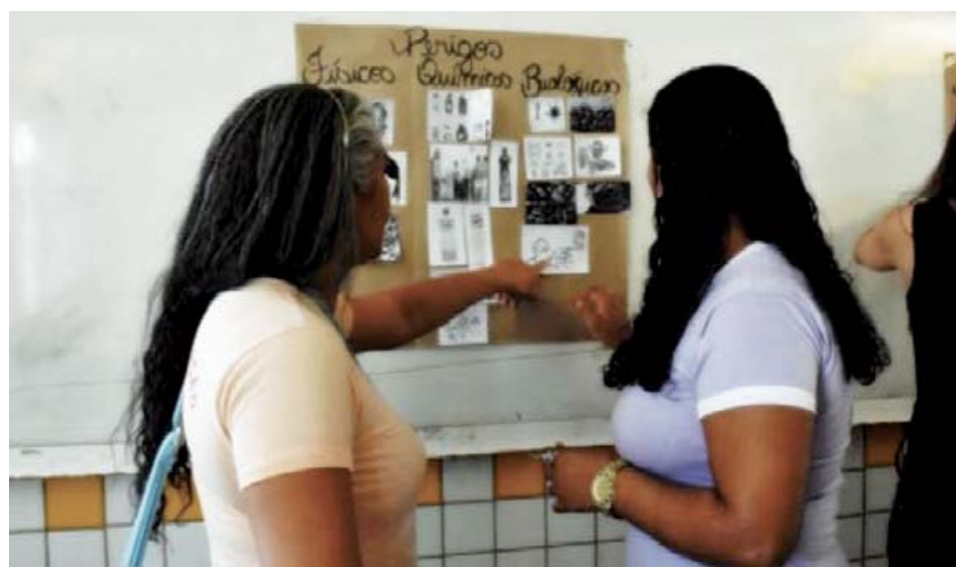

Figura 01: Dinâmica: risco físico, químico e biológico.

Fonte: Arquivo próprio. 
Em seguida, o representante, auxiliado pelo grupo, fez uma rápida explanação com as justificativas e considerações sobre as escolhas feitas para todos os presentes. Durante o desenvolvimento da atividade os participantes interagiram entre si de forma harmônica, compartilhando vivências e relatando casos ocorridos no seu ambiente de trabalho, dentro do contexto do assunto abordado na dinâmica.

O modo como foi conduzido às oficinas na forma de metodologia participativa, com problematização das ações, utilização de dinâmicas e jogos, aperfeiçoou a participação e compreensão dos participantes sobre os perigos iminentes na manipulação dos alimentos. Modesto e Rubio (2014) destacam o aspecto lúdico como importante instrumento na mediação do processo de aprendizagem, favorecendo o uso do pensamento, a concentração e o diálogo, assim como o desenvolvimento social, pessoal e cultural, facilitando o processo de construção do pensamento.

A quarta etapa foi pautada na atividade do checklist, onde todas as merendeiras receberam um roteiro para auxílio na listagem de conformidades e não conformidades que elas fossem capazes de identificar no ambiente de trabalho. O objetivo dessa atividade foi estimular a percepção do profissional em relação ao seu ambiente de trabalho e identificar as condições das instalações, equipamentos e utensílios envolvidos no preparo dos alimentos, fatores esses que impactam diretamente na segurança alimentar e na salubridade do local de trabalho.

A RDC, $\mathrm{n}^{\circ} 275$ (BRASIL, 2002), traz um checklist estruturado com a finalidade de estabelecer Procedimentos Operacionais Padronizados ( $\left.\mathrm{POP}^{\prime} \mathrm{s}\right)$ que contribuem para a garantia das condições higiênico-sanitárias necessárias ao processamento/industrialização de alimentos, complementando as Boas Práticas de Fabricação. Ser capaz de identificar não conformidades na rotina de trabalho; segundo Bordenave e Pereira (2004) é importante, assim como uma eficiente estratégia de ensinoaprendizagem através da problematização, o chamado Arco de Maguerez, que envolve a observação da realidade, o estabelecimento de pontos-chaves, a teorização, as hipóteses de solução e aplicação à realidade. A identificação e crítica participativa da realidade são passos importantes para a adoção consciente de POP's e modificação da realidade social dos envolvidos nesse tipo de capacitação.

Diante da grande diversidade das escolas em que os responsáveis pela alimentação escolar estão inseridos, houve diferentes posicionamentos a respeito das conformidades e inconformidades demonstrando que diversas realidades sociais exigem a participação ativa da merendeira em transformar a teorização a que foi exposta em tomadas de decisão eficientes que levará à mudança intencional de seus procedimentos e, por conseguinte, do resultado final que é a segurança alimentar e o bem-estar laboral da merendeira (BERBEL, 1999).

A quinta etapa, desenvolvida na capacitação dos atores, consistiu na condução da dinâmica: "Árvore do progresso" (Figura 4). Inicialmente os participantes foram orientados a fazerem uma análise das questões avaliadas no checklist. Para a realização da dinâmica eles receberam papéis coloridos, verde, amarelo e vermelho, cortados em formato de folhas, flores e frutos, respectivamente. Nos de cores verdes em formato de folha, deveriam escrever o que estava ruim e precisava mudar; nos de cores amarelas em formato de flor escreveram o que estava bom, mas que poderia ser melhorado e nos de cores vermelhas em formato de fruta, o que estava ótimo e não precisava mudar. Em seguida, cada grupo elegeu um representante que apresentou os fatores discutidos nos grupos e colaram os recortes nos painéis em formato de árvores expostos na parede.

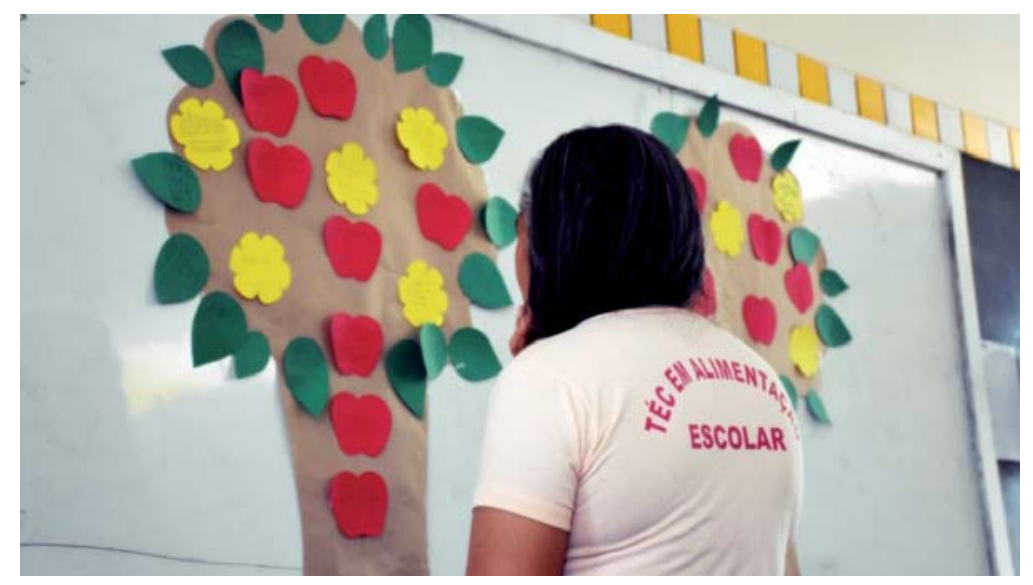

Figura 2 - Dinâmica: árvore do progresso

Fonte: Arquivo próprio 
Ao final desta atividade foi possível observar que diversos problemas são identificados nas cozinhas escolares, sendo alguns relatados com maior frequência pelos participantes, tais como: número reduzido de funcionários envolvidos na produção de alimentos, sobrecarga das merendeiras, ausência de uniformes e falta ou precariedade de utensílios e equipamentos nas escolas.

As oficinas apresentam uma forma tranquila e prazerosa de aprender, além de promover uma maior interação entre os envolvidos propiciando uma aula agradável e permitindo aos participantes uma maior assimilação (CADORIN \& MORANDINI, 2014). Para encerrar as oficinas foi feita uma leitura de um texto motivacional, abordando a valorização de cada indivíduo como elemento fundamental para o processo de trabalho, assim como a importância do diálogo e cooperação no trabalho em equipe.

Em relação à aprendizagem, os depoimentos dos participantes sinalizaram um bom aproveitamento, conforme mostra uma narrativa abaixo:

\begin{abstract}
“Estamos todos cansados! Sair de casa em um sábado pela manhã e deixar sua casa e família para estar aqui, tentar esquecer todos os problemas que ficou em casa e tentar se envolver nas atividades desenvolvidas aqui, é difícil! Mas vocês conseguiram tirar de mim muitos risos, deixou nosso sábado mais leve, gostei muito".
\end{abstract}

\title{
Conclusões
}

As dinâmicas foram realizadas de modo não convencional, a luz da compreensão da metodologia participativa referenciada por Paulo Freire, como importante ferramenta para a participação efetiva e ativa do grupo de interesse, proporcionando uma melhor assimilação dos conteúdos programáticos para atender as necessidades do PNAE.

A capacitação e a valorização do trabalho das merendeiras representam um fator primordial para a transformação da alimentação escolar, mas, para isso, são necessários esforços sociais e educacionais permanentes para o aperfeiçoamento do processo de trabalho de modo a contribuir com a segurança e qualidade dos alimentos oferecidos.

As oficinas tiveram boa adesão dos participantes, sendo capaz de promover debate e reflexão sobre a temática abordada, reconhecendo, assim, a metodologia utilizada, uma boa base para elaboração de capacitações de merendeiras ligadas à alimentação escolar.

\section{Fontes de Financiamento}

O presente estudo não recebeu apoio financeiro.

\section{Referências}

BERBEL, N.A.N. Metodologia da problematização: fundamentos e aplicações. Londrina: Ed. INP/UEL; 1999.

BRASIL. Estatuto da criança e do adolescente. Lei 8.069, de 13 de Julho de 1990 e legislação correlata [recurso eletrônico]. 9. ed. Brasília. Câmara dos Deputados, Edições Câmara, 2012.

BRASIL. Ministério da Educação e Cultura. Por uma política de valorização dos trabalhadores em educação: em cena, os funcionários da escola. Brasília (DF): Ministério da Educação e Cultura; 2004.

BRASIL. Ministério da Educação. Programa Nacional de Alimentação Escolar. Brasília: Fundo Nacional de Desenvolvimento da Educação; 2004.

BRASIL. Ministério da Saúde, Secretaria de Vigilância em Saúde, Departamento de Vigilância Epidemiologia. Manual integrado vigilância, prevenção e controle de doenças transmitidas alimentos. Brasília, 2010.

BRASIL. Ministério da Saúde. Secretaria da Vigilância Sanitária. Portaria $n^{\circ}$ 216, de 15 de setembro de 2004. Aprova o regulamento técnico de boas práticas para serviços de alimentação. Diário Oficial da União; Poder Executivo, 2004. 
BRASIL. Resolução - RDC $N^{0}$ 275/ 02. Dispõe sobre o Regulamento Técnico de Procedimentos Operacionais Padronizados aplicados aos Estabelecimentos Produtores/Industrializadores de Alimentos e a Lista de Verificação das Boas Práticas de Fabricação em Estabelecimentos Produtores/ Industrializadores de Alimentos. In: Diário Oficial da União, Brasília, 2002.

BORDENAVE, J.D.; PEREIRA, A.M.P. Estratégias de ensino-aprendizagem. 25a ed. Rio de Janeiro: Vozes; 2004.

CADORIN, C.T.; MORANDINI, L.P. Olhar psicopedagógico na prática da ludicidade. Revista de Educação do Ideau. Auto Uruguai, v. 9, n.20, p. 1-13, 2014.

CAMPOS, J.A.D.B.; ZUANON, A.C.C. Merenda escolar e promoção de saúde. Revista Ciência Odontológica Brasileira, v. 7, n. 3, p. 67-71, 2004.

FERNANDES, A.G.S.; FONSECA, A.B.C.; SILVA, A.A. Alimentação escolar como espaço para educação em saúde: percepção das merendeiras do município do Rio de Janeiro, Brasil. Revista Ciência E Saúde Coletiva, v.19, n.1, p.39-48, 2014.

FREIRE, P. Pedagogia da Autonomia. São Paulo, Editora Paz e Terra, 2007.

FREIRE, P. Pedagogia do Oprimido. São Paulo, Editora Paz e Terra, 1996.

GERMANO, M.I.S. Promoção da saúde: desafio para os profissionais envolvidos no treinamento de manipuladores de alimentos [tese]. São Paulo: Universidade de São Paulo; 2002.

LATORRES, J.M. Utilização de pescado na elaboração de produto destinado à merenda escolar. [tese]. Rio grande do sul: escola de química e alimentos programa de pós-graduação em engenharia e ciência de alimentos,2014

LEITE, C.L.; CARDOSO, R.C.V.; GÓES, J.A.W.; FIGUEIREDO, K.V.N.A.; SILVA, E.O.; BEZERRIL, M.M.; JUNIOR, P. O. V. Formação para merendeiras: uma proposta metodológica aplicada em escolas estaduais atendidas pelo programa nacional de alimentação escolar, em Salvador, Bahia. Revista de Nutrição. v. 24, n.2, p.275-285, 2011.

MENEGAZZO, M.; FRACALOSSI,K.; FERNANDES, A.C.; MEDEIROS, N.I. Avaliação qualitativa das preparações do cardápio de centros de educação infantil. Revista de Nutrição. Campinas, v.24 n.2, p.243-251, 2011.

MODESTO, M.C.; RUBIO, J. A.S. A Importância da Ludicidade na Construção do Conhecimento. Revista Eletrônica Saberes da Educação. São Roque, v. 5, n. 1, p.1-16, 2014.

NUNES, B.O. O sentido do trabalho para merendeiras e serventes em situação de readaptação nas escolas públicas do Rio de Janeiro [dissertação]. Rio de Janeiro: Fundação Oswaldo Cruz, Escola Nacional de saúde pública; 2000.

SOARES, L.S.; ALMEIDA, R.C.C.; CERQUEIRA, E.S.; CARVALHO, J.S.; NUNES, I.L. Knowledge, attitudesandpractices in foodsafetyandthepresenceof coagulase-69 positive staphylococcionhandsoffoodhandlers in theschoolsof Camaçari, Brazil. FoodControl, v. 27, p. 206213, 2012.

TEO, C.R.P.A.; SABEDOT,F. R.B.S.; SCHAFER, E. Merendeiras como agentes de educação em saúde da comunidade escolar: potencialidades e limites, Revista Espaço para a Saúde, Londrina, v. 11, n. 2, p. 11-20, 2010.

Recebido para publicação em 3/8/2017 e aprovado em 30/10/2017. 